\title{
Optical and Radiative Properties of Aerosols over Two Locations in the North-West Part of India during Premonsoon Season
}

\author{
Yogesh Kant, ${ }^{1}$ Atinderpal Singh, ${ }^{2}$ Debashis Mitra, ${ }^{1}$ Darshan Singh, ${ }^{2}$ P. Srikanth, \\ A. S. Madhusudanacharyulu, ${ }^{1}$ and Y. N. V. Krishna Murthy ${ }^{1}$ \\ ${ }^{1}$ Indian Institute of Remote Sensing, ISRO, Department of Space, Government of India, Dehradun, India \\ ${ }^{2}$ Physics Department, Punjabi University, Patiala, India \\ Correspondence should be addressed to Yogesh Kant; ykanty@yahoo.com
}

Received 5 March 2014; Revised 23 June 2014; Accepted 7 August 2014

Academic Editor: Umesh C. Dumka

Copyright (C) 2015 Yogesh Kant et al. This is an open access article distributed under the Creative Commons Attribution License, which permits unrestricted use, distribution, and reproduction in any medium, provided the original work is properly cited.

\begin{abstract}
The present study examines the aerosol characteristics over two locations in the northwest region of India (Dehradun and Patiala) during premonsoon season of 2013. The average mass concentrations of particulates $\left(\mathrm{PM}_{10} ; \mathrm{PM}_{2.5} ; \mathrm{PM}_{1}\right)$ were found to be $118 \pm 36$, $34 \pm 11$, and $19 \pm 10 \mu \mathrm{gm}^{-3}$ and $140 \pm 48,30 \pm 13$, and $14 \pm 06 \mu \mathrm{gm}^{-3}$ over Dehradun and Patiala, respectively. The average aerosol optical depth $\left(\mathrm{AOD}_{500 \mathrm{~nm}}\right)$ is observed to be $0.62 \pm 0.11$ over Dehradun and $0.56 \pm 0.21$ over Patiala. Ångström exponent and fine mode fraction show higher values over Dehradun as compared to Patiala. The average mass concentration of black carbon was found to be $3343 \pm 546 \mathrm{ngm}^{-3}$ and $6335 \pm 760 \mathrm{ngm}^{-3}$ over Dehradun and Patiala, respectively. The diurnal pattern of BC is mainly controlled by boundary layer dynamics and local anthropogenic activities over both the stations. The average single scattering albedo $\left(\mathrm{SSA}_{500 \mathrm{~nm}}\right)$ exhibited low value over Patiala $(0.83 \pm 0.01)$ in comparison to Dehradun $(0.90 \pm 0.01)$, suggesting the abundance of absorbing type aerosols over Patiala. The average atmospheric aerosol radiative forcing is $+37.34 \mathrm{Wm}^{-2}$ and $+54.81 \mathrm{Wm}^{-2}$ over Dehradun and Patiala, respectively, leading to atmospheric heating rate of $1.0 \mathrm{~K} \mathrm{day}^{-1}$ over Dehradun and $1.5 \mathrm{~K} \mathrm{day}^{-1}$ over Patiala.
\end{abstract}

\section{Introduction}

The atmospheric aerosols exert both direct and indirect forcing on climate by perturbing Earth's radiation budget [14]. The direct effect refers to the interaction of aerosols with radiation through absorption or scattering, and the indirect effect results from the modification of microphysical properties of clouds by aerosols that act as cloud condensation nuclei (CCN) which in turn affect the cloud albedo, cloud life time, and precipitation rate [5]. It is still uncertain whether aerosols have net cooling or warming effect on Earth's atmosphere because of inadequate knowledge of regional and global aerosol characteristics and their temporal variation. These effects are directly related with the regional atmospheric radiative forcing which may affect the climate at regional to global scale. Aerosol radiative forcing (ARF) mainly depends on spectral aerosol optical depth (AOD), water vapor content, ozone content, asymmetry parameter $(g)$, surface albedo, single scattering albedo (SSA), and vertical distribution of aerosols. Out of these, SSA, which is the ratio of scattering to extinction, is an important parameter affecting the ARF and is highly sensitive to the relative distribution of scattering and absorbing type aerosols in the atmosphere. Aerosols such as black carbon (BC) significantly absorb radiation in the visible and IR spectrum leading to atmospheric warming and a surface cooling [6]. The study of $\mathrm{BC}$ aerosol at high altitude sites in the Himalayas is particularly important for understanding their role in radiative forcing and, more importantly, the deposition and melting of Himalayan glaciers [7, 8]. Major contribution to high altitude $\mathrm{BC}$ is associated with the longrange transport $[7,9,10]$ and local emissions from the IndoGangetic Plain (IGP) $[8,11,12]$. The present study is focused on the assessment of optical and radiative characteristics of aerosols and $\mathrm{BC}$ variation during the premonsoon season (April-June, 2013) over two locations at Dehradun and Patiala in the north-west region of India. During this season, dust storms occasionally hit the northwestern part of India mostly originating from Thar Desert [13]. During the study 
period, the ground based measurements have been used in conjunction with satellite observations and the aerosol radiative forcing is estimated using model simulations.

\section{Site Description and Meteorology}

2.1. Dehradun (Lat: $30.30^{\circ} \mathrm{N}$, Long: $78.03^{\circ} \mathrm{E}, 700 \mathrm{~m}$ above Mean Sea Level). Dehradun is the capital of Uttarakhand state and located at the foot hills of Himalayas. The valley is characterized by undulation topography, prominently influenced by transport of pollutant from the IGP. The study site is surrounded by hills of high altitude $(2000 \mathrm{~m})$ in the direction of north and east. Dehradun experiences high vehicular traffic throughout the year due to tourist spots around it. During study period, the average day time temperature and relative humidity $(\mathrm{RH})$ was $33^{\circ} \mathrm{C}$ and $51 \%$, respectively, and the wind is normally northwesterly with speed of less than $1 \mathrm{~ms}^{-1}$.

2.2. Patiala $\left(30.33^{\circ} \mathrm{N}, 76.4^{\circ} \mathrm{E}, 249 \mathrm{~m}\right.$ above Mean Sea Level). Patiala is located in the south east part of Punjab. The sampling site is surrounded by agricultural fields and industrial cities like Ludhiana and Gobindgarh located in the north-west of the sampling site. More details of the site description are described elsewhere [14, 15]. During the present study, average maximum day time temperature was $36^{\circ} \mathrm{C}$ whereas the $\mathrm{RH}$ was low (41\%). The wind was normally northwesterly/southwesterly with average speed of $2 \mathrm{~ms}^{-1}$. Both sites experienced frequent and heavy rainfall spells all over the month of June. The total rainfall recorded in June at Dehradun and Patiala was $1030 \mathrm{~mm}$ and $145 \mathrm{~mm}$, respectively.

\section{Data Sets and Methodology}

MICROTOPS-II (MT) sun photometer [16] was used to measure spectral aerosol optical depth (AOD; 380-870 nm) and aerosol spectrometer (GRIMM; model 1.108) was used to assess the mass distribution $\left(\mathrm{PM}_{10}, \mathrm{PM}_{2.5}\right.$, and $\left.\mathrm{PM}_{1}\right)$ of aerosols over both locations. The aerosol spectrometer was operated thrice a week (0900-1700 hrs) during the premonsoon season for same days at both the stations. The cumulative error in AOD measurements due to Rayleigh scattering and molecular absorption is found to be $2 \%-5 \%$ for MT sun photometers at different wavelengths [17]. Details of AOD analysis has been reported in our earlier work [18]. The measuring principle of aerosol spectrometer is based on the light scattered by individual particle incident from semiconductor laser in a measuring cell. The scattered light pulse from every single particle is being counted and intensity of scattered light signal is classified to certain particle size. After the detection of the particle concentration and its size, the size distribution of aerosols can be determined and this in turn is the basis for the evaluation of the particulate mass. The measurement of $\mathrm{BC}$ mass concentration was carried out at both sites using 7-wavelength aethalometer (Model AE31, Magee Scientific Company, Berkley, CA, USA) online monitor with temporal resolution of 5 minutes during study period. It measures the optical attenuation (absorbance) of light from LED lamps emitting at seven wavelengths (370, $470,520,590,660,880$, and $950 \mathrm{~nm}$ ) with a typical halfwidth of $20 \mathrm{~nm}$ [19]. Observations at $880 \mathrm{~nm}$ are considered as standard for BC measurement, as BC is principal absorber at this wavelength in comparison to the other aerosol species. The analytical uncertainty in BC measurements is $\sim \pm 2 \%$ (as reported in aethalometer user manual). However, occasionally, it has been reported that the mass concentration of $\mathrm{BC}$ aerosol can be overestimated due to presence of other absorbing aerosol [20]. The uncertainty in BC mass measurement due to shadow effect and multiple scattering has been studied earlier [21, 22], and same has been considered in the present analysis and found that the uncertainty does not exceed over 10\% [15]. More details on the analytical technique of aethalometer can be found elsewhere $[23,24]$. A semiempirical model, optical properties of aerosols and clouds (OPAC), was used to derive the optical properties of aerosols [25] synchronous with the ground observations. Keeping in view of the composition of aerosols over both the sites, five different aerosol types (soot, water soluble, insoluble, mineral accumulation, and mineral transport) as externally mixed particles forming the composite aerosols were fixed in the OPAC model. Angström exponent was calculated from spectral information from ground measured AOD while SSA and asymmetric parameter were simulated using OPAC model. In accordance with the ground measured $\mathrm{BC}$ concentration, the $\mathrm{BC}$ mass mixing ratio (ratio of the mass concentration of $\mathrm{BC}$ to the total mass of the composite aerosols) was fixed while the number densities of other components were varied. A number of iterations was performed till the estimated spectral AOD was in close agreement with the sun photometer based measured values [26]. In the present analysis, only those data sets have been considered where the root mean square difference between the simulated spectral AOD and measured spectral AOD is less than or equal to 0.03 as shown in Figure 1 [27].

The aerosol radiative forcing at top of the atmosphere and at the surface is defined as the change in the net radiative flux with and without aerosols. The estimated atmospheric aerosol radiative forcing (ATM) is the difference between surfaces radiative forcing (SRF) and the radiative forcing at the top of the atmosphere (TOA). The sign and magnitude of atmospheric forcing due to aerosol depends upon the nature of aerosols, their distribution, and planetary albedo. The surface albedo was calculated using MODIS albedo product (MODIS/Terra + Aqua albedo 16-day L3 global $1 \mathrm{~km}$ SIN Grid V005). Aerosol radiative forcing (ARF) over both locations was estimated using Santa Barbara DISORT atmospheric radiative transfer (SBDART) model [28]. The aerosol optical depth (AOD), Ångström exponent $(\alpha)$, single scattering albedo (SSA), asymmetry parameter $(g)$, and spectral albedo were used as an input to SBDART to compute aerosol radiative forcing at the surface (SRF) and top of the atmosphere (TOA). The uncertainties in shortwave ARF calculations could arise from various assumptions, such as model atmosphere and OPAC simulations, as well as uncertainties in surface albedo, molecular scattering, and absorption and errors in measured parameters, such as $\mathrm{AOD}$ and $\mathrm{BC}$ mass concentration. The overall uncertainty 

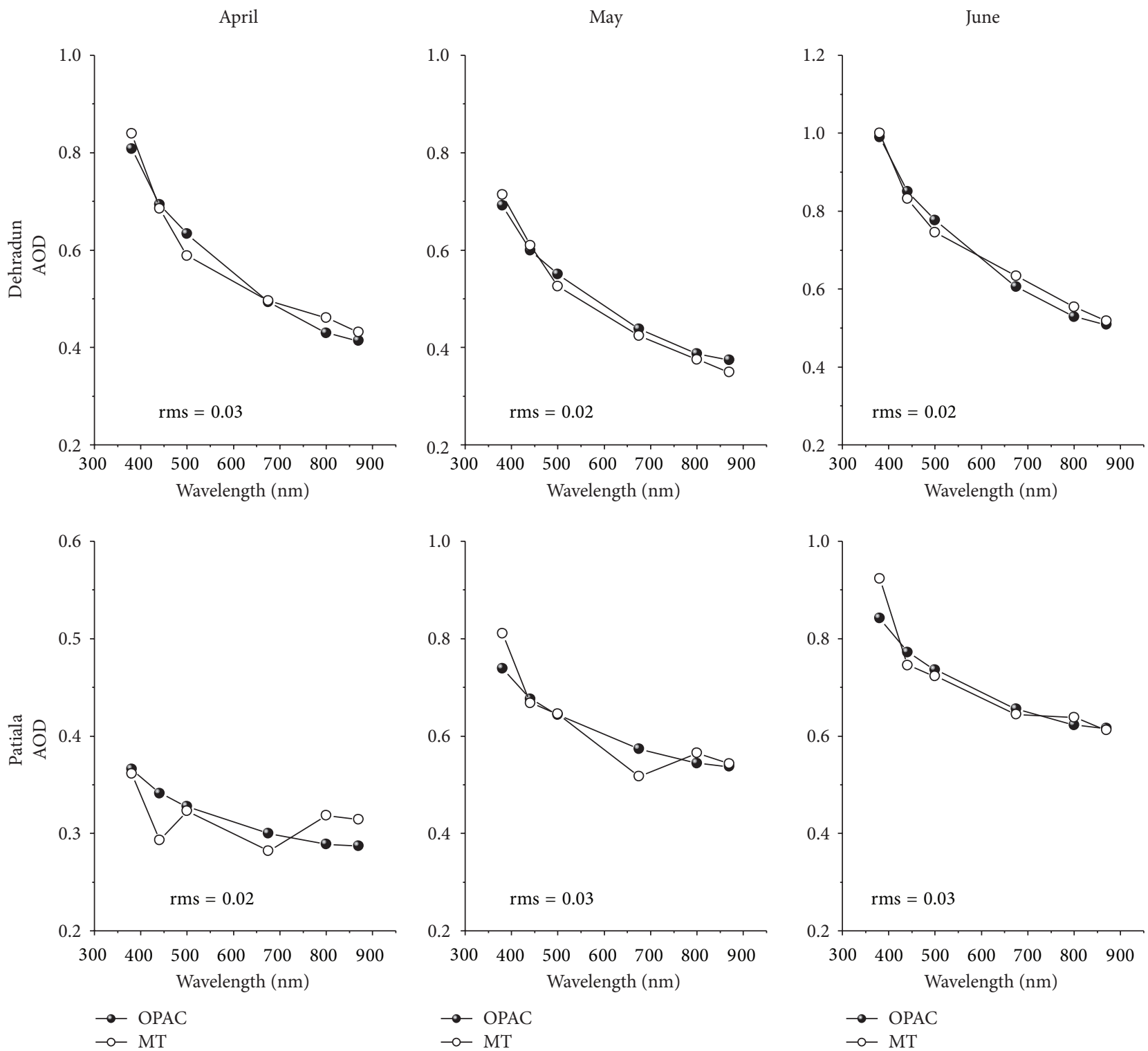

FIGURE 1: Intercomparison of OPAC derived spectral AOD with Sunphotometer measured spectral AOD over Dehradun and Patiala.

in ARF calculations is within the range of $20 \%$ [18, 29]. The AOD was derived from moderate resolution imaging spectroradiometer (MODIS) onboard polar orbiting NASA's Earth Observing System (EOS) Terra and Aqua level 3 data products at $550 \mathrm{~nm}$ and at $388 \mathrm{~nm}$ and $500 \mathrm{~nm}$ for Aura Satellite (OMAERUVd.003) level 3 data products. More detail about algorithm and functioning of MODIS are described elsewhere $[18,30,31]$. MODIS provides AOD data at $0.1^{\circ} \times$ $0.1^{\circ}$ grid whereas AURA provides at $0.25^{\circ} \times 0.25^{\circ}$ grid interval. The satellite data was used through 20 to $34^{\circ} \mathrm{N}$ latitude covering north and north-west Himalayan region, part of Indo-Gangetic Plain, and western and part of central Indian regions. It is observed that all aerosol optical properties values are not available for each grid level. Hence, to obtain a continuous surface for each point grid, interpolation technique was used to generate AOD values for entire area in $1 \mathrm{~km}$ grid size. The AOD retrieved from satellite data was validated with the ground based measurements. The continuous AOD data generated over the selected Indian region would help in estimating Aerosol Radiative Forcing.

\section{Results and Discussion}

The variations of $\mathrm{PM}_{10}, \mathrm{PM}_{2.5}$, and $\mathrm{PM}_{1}$ mass concentrations during premonsoon season over both locations are shown in Figure 2(a). The seasonal average mass concentration of particulates $\left(\mathrm{PM}_{10}, \mathrm{PM}_{2.5}\right.$, and $\left.\mathrm{PM}_{1}\right)$ was found to be $118 \pm$ 36, $34 \pm 11$, and $19 \pm 10 \mu \mathrm{g} \mathrm{m}^{-3}$ over Dehradun and $140 \pm$ $48,30 \pm 13$, and $14 \pm 06 \mu \mathrm{g} \mathrm{m}^{-3}$ over Patiala suggesting higher concentration of coarser particulate $\left(\mathrm{PM}_{10}\right)$ while lower concentration of fine particulates $\left(\mathrm{PM}_{2.5}\right.$ and $\left.\mathrm{PM}_{1}\right)$ over 


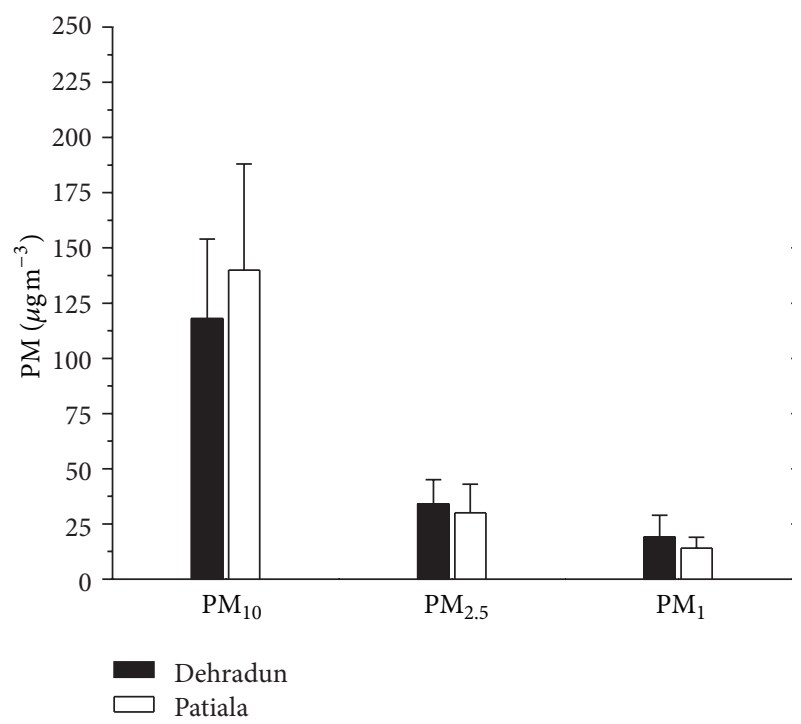

(a)
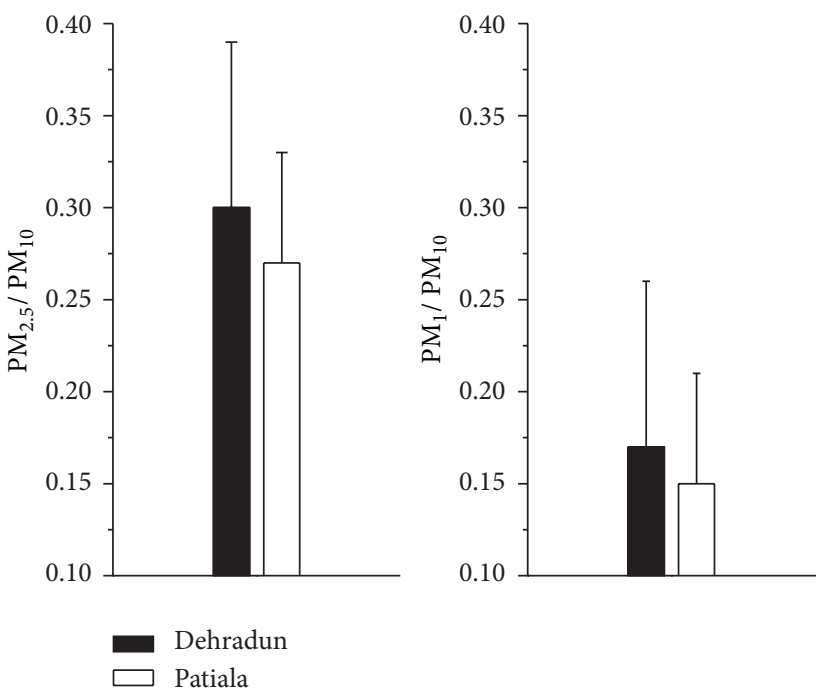

(b)

FIGURE 2: The variation of seasonal average (a) particulate mass concentration $\left(\mathrm{PM}_{10}, \mathrm{PM}_{2.5}\right.$, and $\left.\mathrm{PM}_{1}\right)$ and (b) FMF over Dehradun and Patiala.

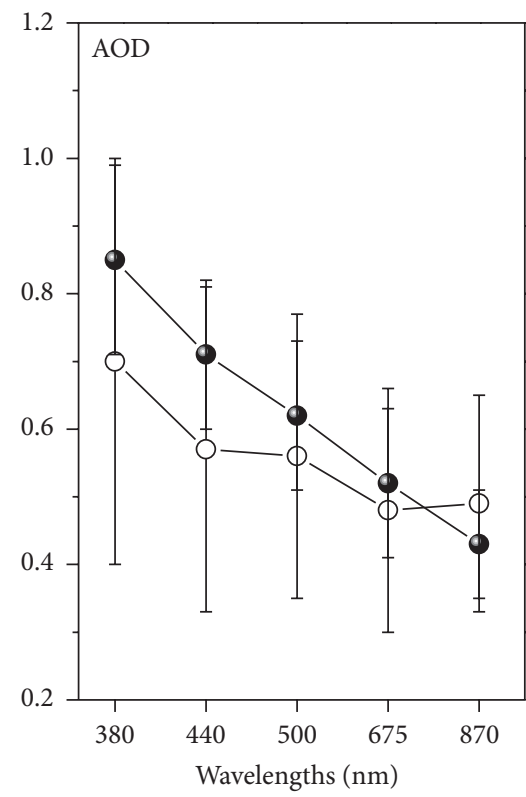

(a)

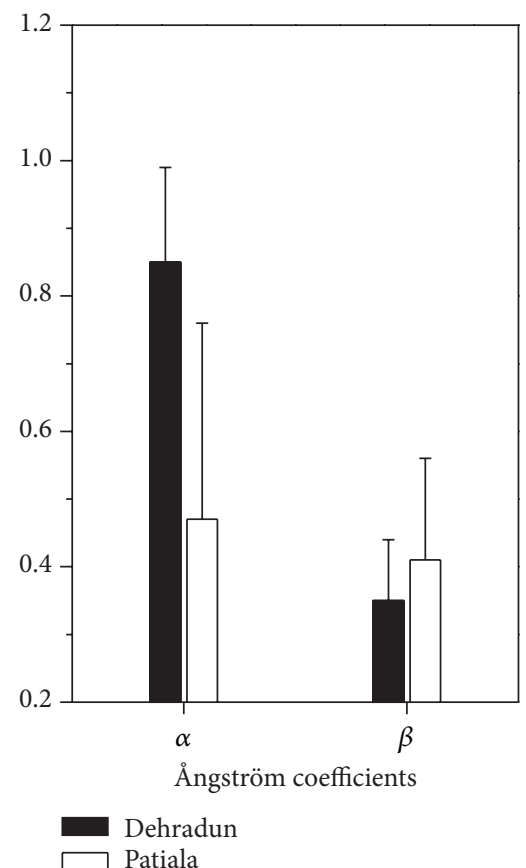

(b)

Figure 3: The variation of seasonal average (a) spectral AOD and (b) Ångström coefficient (380-870 nm) over Dehradun and Patiala.

Patiala as compared to Dehradun. The estimated fine mode fraction (FMF) over both locations (Figure 2(b)) reveals the relative dominance of fine and coarse mode particles. The magnitude of FMF is high over Dehradun $\left(\mathrm{PM}_{2.5} / \mathrm{PM}_{10}=\right.$ 0.30 and $\left.\mathrm{PM}_{1} / \mathrm{PM}_{10}=0.17\right)$ in comparison to Patiala $\left(\mathrm{PM}_{2.5} / \mathrm{PM}_{10}=0.22\right.$ and $\left.\mathrm{PM}_{1} / \mathrm{PM}_{10}=0.10\right)$. From the analysis of FMF over these two sites, it can be concluded that the finer mode particle is abundant over Dehradun and surrounding region as compared to Patiala and surrounding region. The northwestern part of IGP experiences occasional dust storms during the premonsoon season as is evident from dominance of coarser aerosols over Patiala. Dehradun is situated at high altitude and far away from the Thar Desert, so most of the coarse mode aerosols gets settled down during transport 

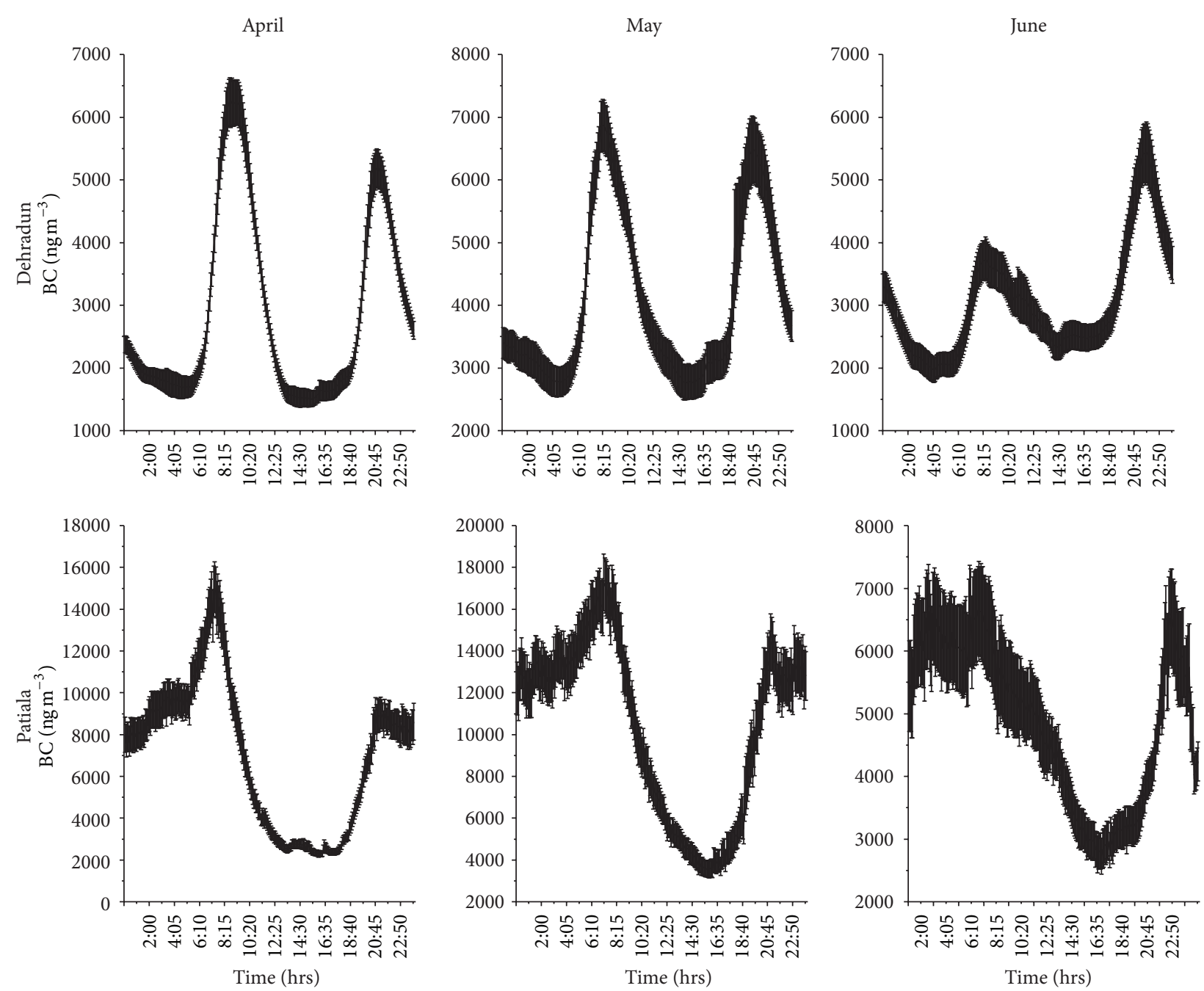

FIGURE 4: The diurnal variation of monthly average BC aerosol over Dehradun and Patiala.

before reaching over Dehradun resulting in less abundance of coarse particles.

The columnar AOD represents the extinction of incoming solar radiation by aerosols and its magnitude is directly proportional to the loading of aerosols in the column. Thus, its assessment is key component in calculating Earth's radiation budget. The variation of seasonal AOD (380-870 nm) over Dehradun and Patiala is shown in Figure 3(a). The seasonal AOD over Dehradun has shown the strong wavelength dependence varying from 0.85 at $380 \mathrm{~nm}$ to 0.43 at $870 \mathrm{~nm}$, while it exhibits weak wavelength dependence over Patiala ranging from 0.70 to 0.49 showing insignificant decrease at longer wavelengths as compared to middle wavelengths. It is interesting to see that, at shorter wavelengths, the magnitude of AOD is higher over Dehradun as compared to Patiala but opposite trend is seen at longer wavelengths. Over Patiala, high value of $A O D$ at longer wavelengths indicates abundance of coarser aerosols over Patiala as compared to Dehradun $[29,32]$ while the strong wavelength dependence of seasonal AOD over Dehradun is attributed to more abundance of fine mode particles due to anthropogenic sources [33]. Further, spectral information of AOD has been used to derive the Angström exponent $(\alpha)$ which is also useful to compare and characterize the wavelength dependence of AOD and columnar aerosol size distribution [34]. The relative increase in number of large sized particles with respect to the smaller ones results in decrease in the value of $\alpha$ and vice versa [35]. In the present analysis, the spectral variation of seasonal AOD was used to derive the Ångström coefficient in wavelength range 380-870 nm (the Ångström exponent " $\alpha$ " and turbidity factor " $\beta$ ") as shown in Figure 3(b). The high value of seasonal Ångström exponent $(\alpha)$ over Dehradun (0.85) as compared to Patiala (0.47) indicates abundance of finer mode particles over Dehradun as compared to Patiala. The variation of Ångström exponent confirms to our findings of size distribution over both locations as inferred from seasonal spectral AOD and FMF analysis. The magnitude of seasonal turbidity factor was found to be 0.35 and 0.41 over Dehradun and Patiala, respectively. The high value of turbidity factor $(\beta)$ over Patiala implies more atmospheric aerosol loading over Patiala especially the coarse mode ones as compared to Dehradun. 
Diurnal variation of black carbon concentrations during the study period over Dehradun is depicted in Figure 4. The diurnal variation of $\mathrm{BC}$ concentration is observed to be low during the day time while peak in morning and evening hours. From the graph it is evident that, for all the months, a sharp peak is observed between 0800 and $0900 \mathrm{hrs}$ local time $\left(6500 \mathrm{ngm}^{-3}\right.$ in April, $6800 \mathrm{ngm}^{-3}$ in May, and $4000 \mathrm{ngm}^{-3}$ in June) and another peak between 1900 and $2200 \mathrm{hrs}$ local time $\left(5500 \mathrm{ngm}^{-3}\right.$ in April, $6800 \mathrm{ngm}^{-3}$ in May, and $6000 \mathrm{ngm}^{-3}$ in June). The morning peak may be attributed to the accumulation of BC particles due to shallow boundary layer and also due to increased anthropogenic activities (particularly during 0700-900 hrs). As the day progresses, solar heating leads to convection resulting in increase of mixed layer height and thereby reducing BC concentration. The concentration decreases till $1700 \mathrm{hrs}$ and then starts increasing gradually due to combined effect of increase in local anthropogenic activities and decrease in boundary layer height. Thus BC concentration again reaches its peak between 1900 and 2200 hrs during all months over Dehradun. Diurnal variation of black carbon concentrations during premonsoon season over Patiala is depicted in Figure 4. Here also, BC concentration is observed to be low during the day time with peaks in the morning and evening hours. It is seen that, during each month, a sharp peak is observed between 0800 and $0900 \mathrm{hrs}$ local time expect in June (16000 $\mathrm{ngm}^{-3}$ in April and $19000 \mathrm{ngm}^{-3}$ in May) and another peak between 1900 and $2200 \mathrm{hrs}$ local time $\left(9000 \mathrm{ngm}^{-3}\right.$ in April, $15000 \mathrm{ngm}^{-3}$ in May, and $7000 \mathrm{ngm}^{-3}$ in June). It is further observed that black carbon concentration is large in May as compared to April and June attributing to $\mathrm{BC}$ emissions from wheat residue burning in the fields during first half of May in Punjab. Over both locations, the morning peak is dominant over evening peak during April and May whereas in June, the evening is dominant over morning peak. The frequent and heavy rainfall was experienced and recorded in the north-west part of India during June. It has been further observed that, at both the locations, rain occurred mostly during morning hours than in late evening hours. This could be the reason for dominance of evening peak in $\mathrm{BC}$ concentration. Seasonal average $\mathrm{BC}$ mass concentration is found to be high over Patiala $\left(6335 \pm 760 \mathrm{ngm}^{-3}\right)$ compared to Dehradun $\left(3343 \pm 546 \mathrm{ngm}^{-3}\right)$. The mass concentration of $\mathrm{BC}$ is influenced by various factors such as transportation due to winds and diurnal variation in the local boundary layer dynamics while the remaining would be from local activities [36].

Aerosols are mainly mixture of both absorbing and scattering type in the atmosphere. Their effect in terms of cooling and warming the atmosphere is dependent upon many parameters, and single scattering albedo (SSA) is amongst the most important parameter [37]. The spectral variation of OPAC simulated seasonal average SSA (380-870 nm) over study regions is shown in Figure 5. The value of seasonal average SSA at $500 \mathrm{~nm}$ is found to be $0.90 \pm 0.01$ and $0.83 \pm 0.01$ over Dehradun and Patiala, respectively. The low value of SSA over Patiala suggests relative abundance of absorbing aerosols over Patiala than Dehradun. The SSA is wavelength

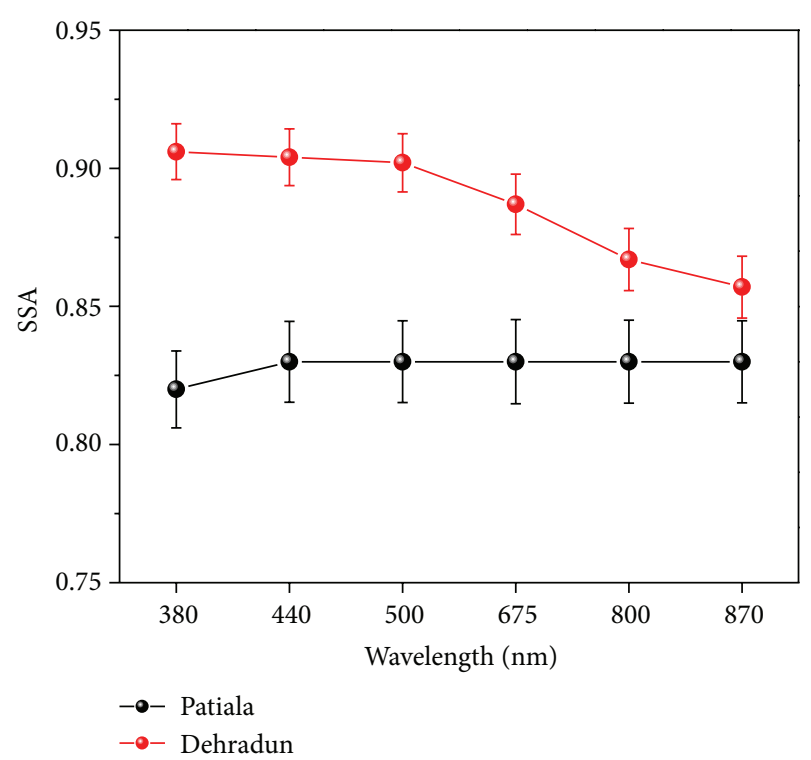

FIGURE 5: The variations of seasonal average spectral SSA over Dehradun and Patiala.

dependent and its magnitude decreases with wavelength over Dehradun and increases with wavelength over Patiala. It shows that the absorption is more prominent at higher wavelengths in comparison to lower wavelengths over Dehradun and the reverse is true for Patiala. The increase of SSA with wavelength over Patiala clearly suggests more scattering at higher wavelengths due to increased concentration of coarse mode particles [32]. The variation of spectral SSA over Patiala is in agreement with the earlier studies over IGP during the premonsoon season $[32,38]$. These studies also reveal the dominance of coarse mode particles (dust aerosols) over the study regions as has been found over Patiala. However, the spectral SSA over Dehradun is opposite to the earlier findings due to less abundance of coarse particles. The opposite trend of spectral SSA variation over Patiala and Dehradun may be attributed to difference in aerosol sources and topography. The spatial variation of AOD at $550 \mathrm{~nm}$ was studied using MODIS Terra and Aqua, while AOD at 380 and $500 \mathrm{~nm}$ was studied using AURA satellite for entire grid level latitude $\left(20-35^{\circ} \mathrm{N}\right)$ over Indian region. Interpolation technique was applied to generate continuous AOD and Ångström exponent values for the entire area. The analysis shows that during April to June the low AOD values (0.01-0.20) are seen over extreme north and central-western region; moderate high values $(0.21-0.51)$ over the central Indian region while high AOD values $(>0.52)$ are seen over north-west region and part of Indo-Gangetic Plains (IGP) (Figure 6). The HYSPLIT air mass back trajectory (5 days) was used over Dehradun and Patiala during April to June at different heights of 500, 1500, and 3000 meters above mean sea level. The analysis shows that over both stations the air masses are from the west and southwest directions which increases the AOD level over north-west part of IGP region (Figure 7). The satellite derived AOD from MODIS and AURA satellites were compared with the ground measured values over the two stations. 

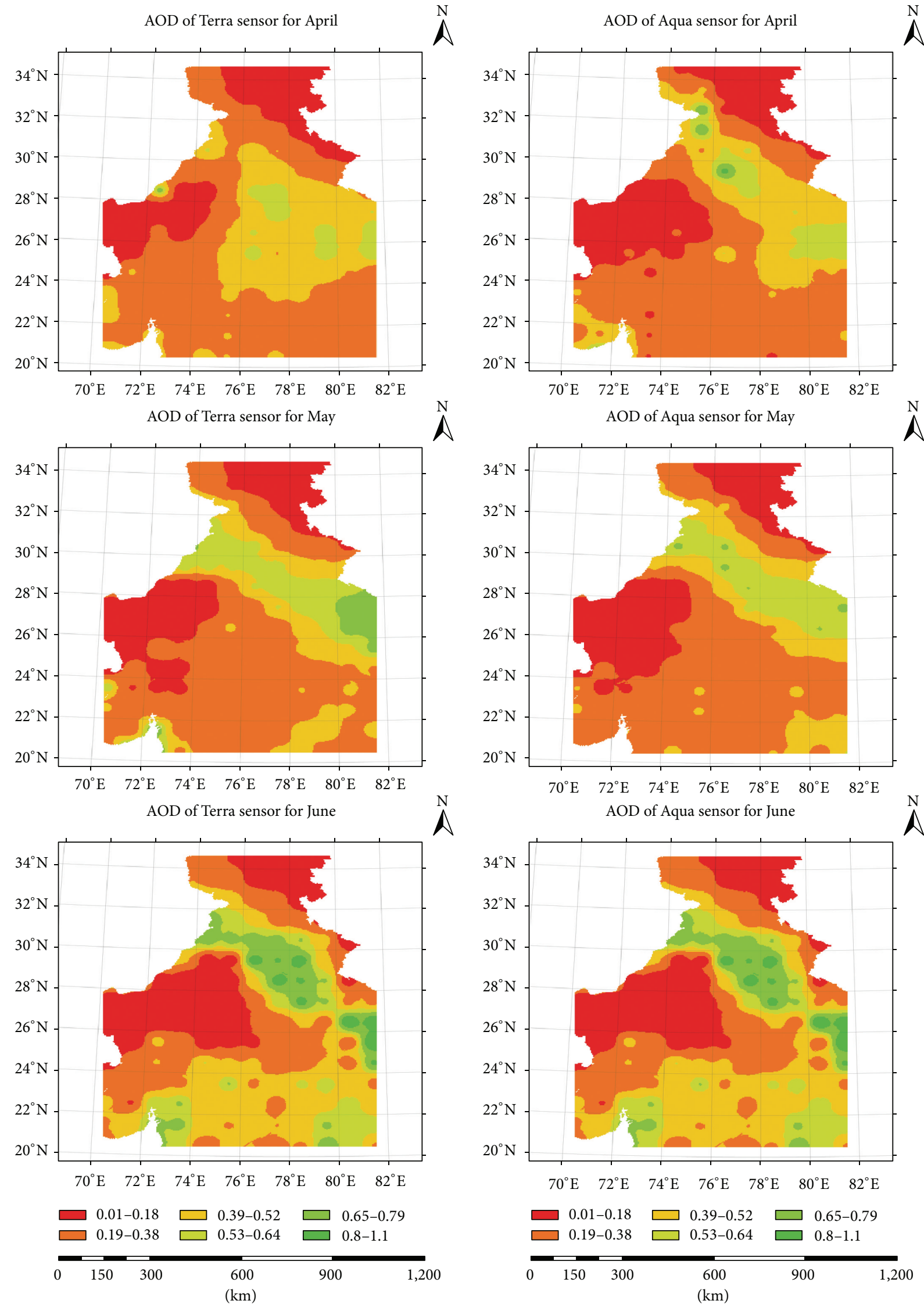

FIGURE 6: Spatial distribution of aerosol optical depth values over the region using MODIS Terra and Aqua data during April to June 2013. 

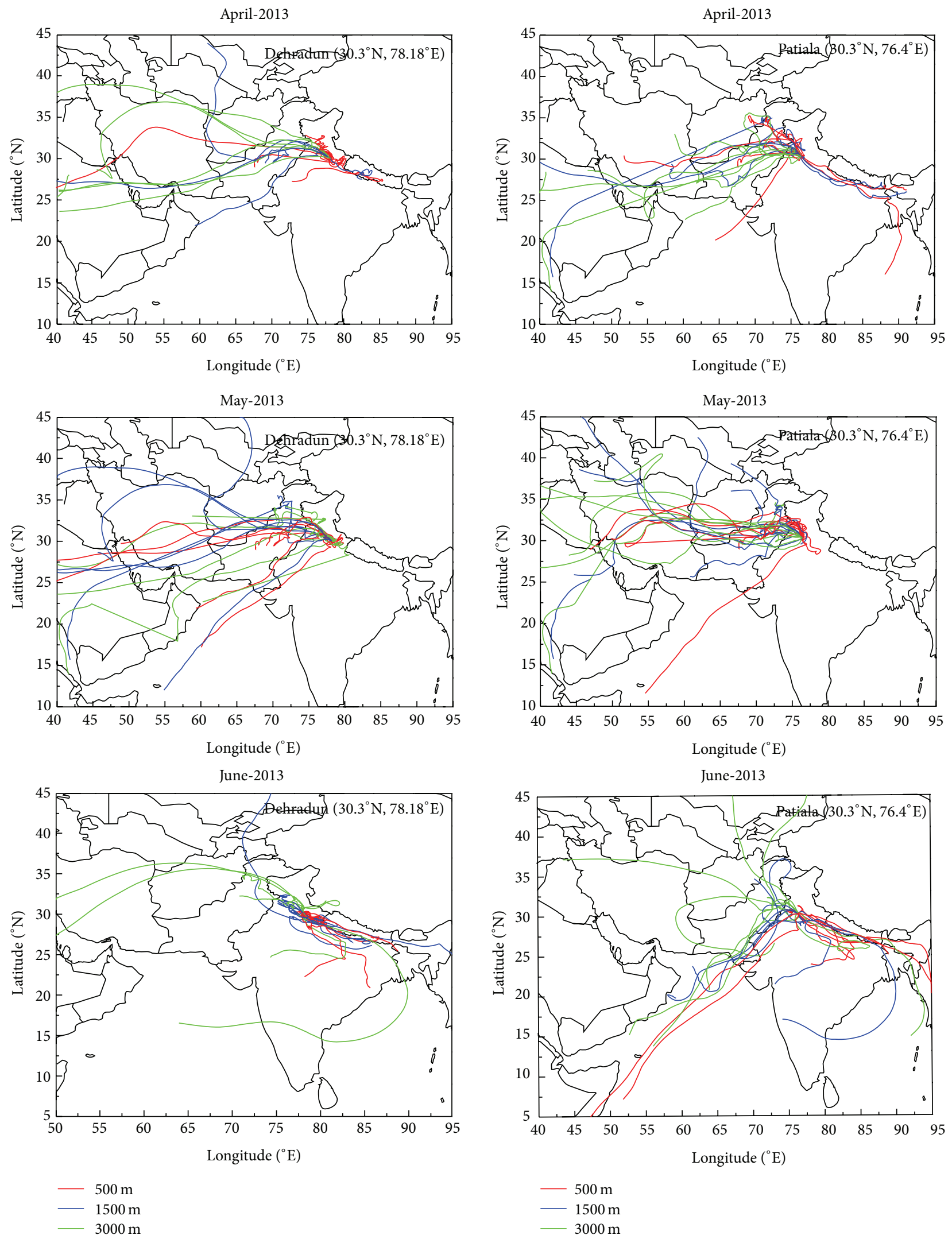

Figure 7: Air mass back trajectory at Dehradun and Patiala stations at three different altitudes during April-June 2013. 


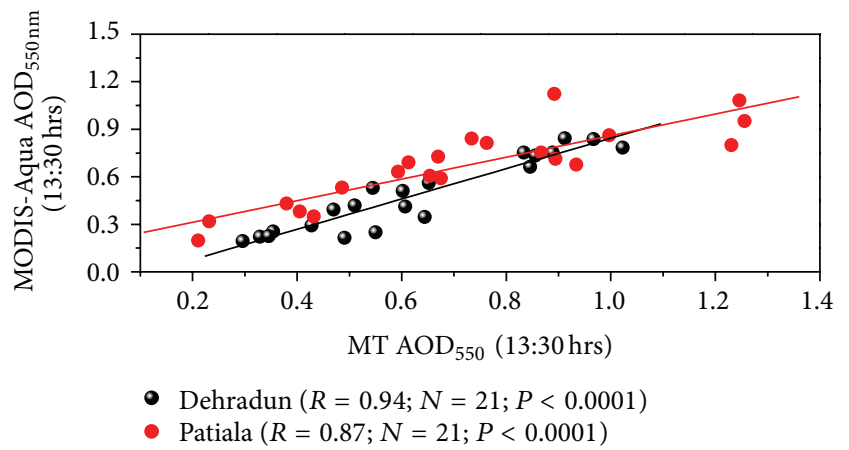

(a)

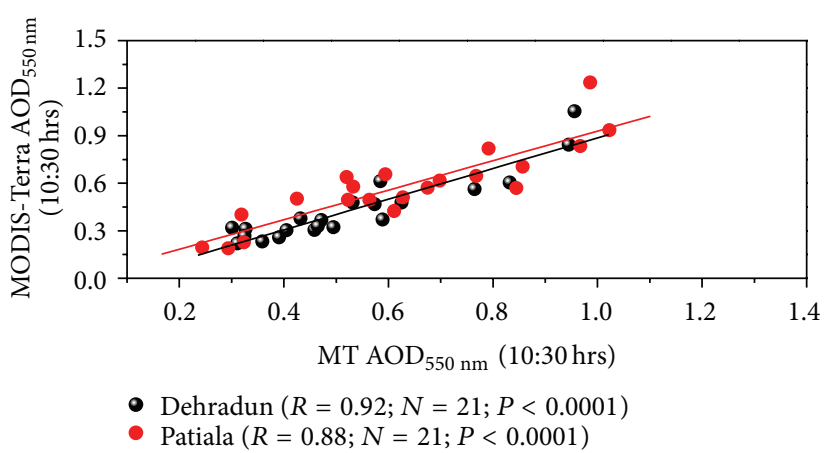

(b)

Figure 8: Correlation of MODIS Terra and MODIS Aqua $\mathrm{AOD}_{550 \mathrm{~nm}}$ versus sun photometer $\mathrm{AOD}_{550 \mathrm{~nm}}$ (at time interval of Terra and Aqua overpass) over Dehradun and Patiala.

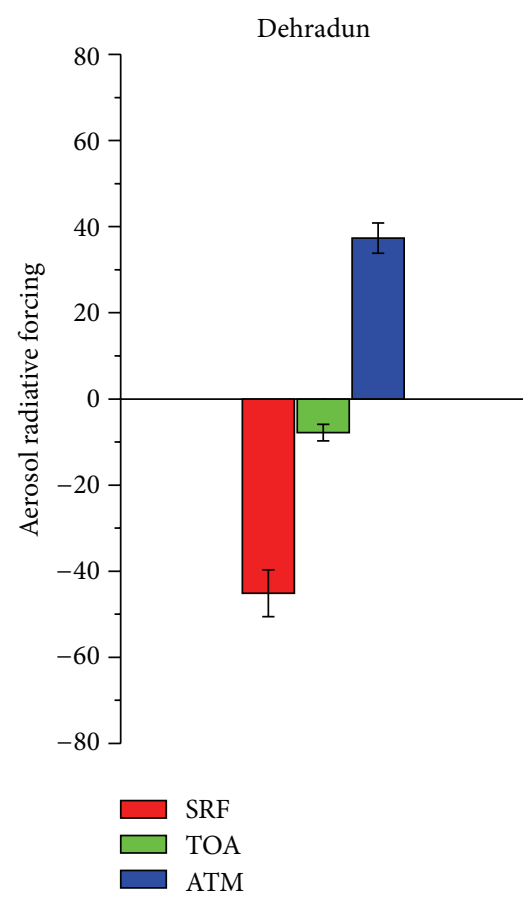

(a)

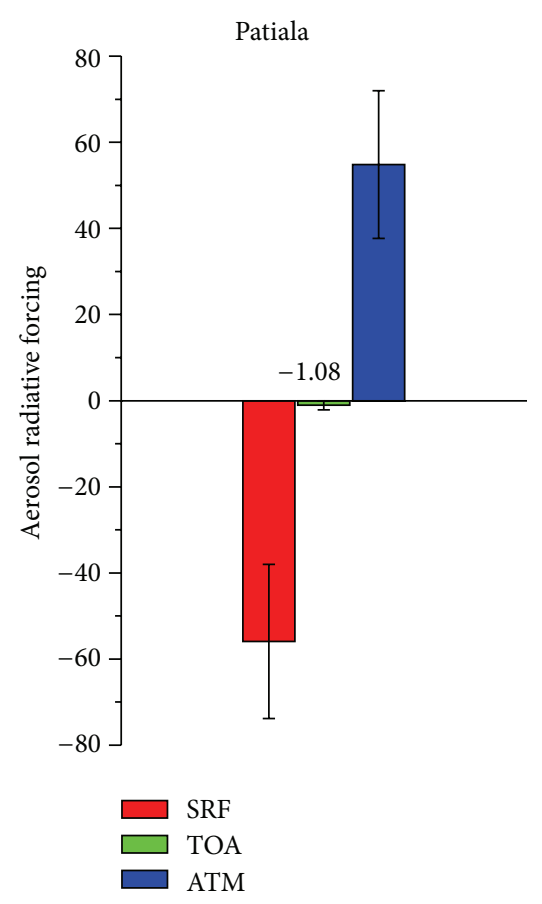

(b)

FIgURE 9: Variation of aerosol radiative forcing at SRF, TOA, and ATM during premonsoon period over Dehradun and Patiala.

The analysis shows that the satellite derived AOD over Dehradun and Patiala is in good agreement $(R=0.94 ; R=$ 0.87 ) with ground measured AOD (Figure 8 ). The variability of seasonal aerosol radiative forcing (ARF) at surface (SRF), top of the atmosphere (TOA), and in atmosphere (ATM) over both locations during the premonsoon season is shown in Figure 9. ARF ATM is estimated to be $+54.81 \mathrm{Wm}^{-2}$ over Patiala and $+37.34 \mathrm{Wm}^{-2}$ over Dehradun. The significant difference between magnitudes of ARF ATM is mainly due to difference of ARF TOA. Over both locations, the TOA is negative with magnitude of $-7.81 \mathrm{Wm}^{-2}$ and $-1.08 \mathrm{Wm}^{-2}$ over Dehradun and Patiala, respectively, indicating more amount of radiation back scattering to space than being received at top of the atmosphere. The high magnitude of ARF TOA over Dehradun suggests dominance of scattering type aerosol than over Patiala. The ARF TOA also depends upon the albedo of the region. The heating rate of atmosphere due to aerosol radiative forcing is estimated during the study period. The seasonal average heating rate is found to be $1.0 \mathrm{~K} \mathrm{day}^{-1}$ and $1.5 \mathrm{~K} \mathrm{day}^{-1}$ over Dehradun and Patiala, respectively. The estimated ATM ARF as well as heating rate is about 3 times higher over Patiala and 2 times higher over Dehradun than over Kanpur and Gandhi College, eastern part of IGP during the premonsoon season as reported earlier [39]. During the other study over IGP in premonsoon season, the ATM $\mathrm{ARF}$ and heating rate is reported to be $+55.43,+56.19$, +50.22 , and $+38.14 \mathrm{Wm}^{-2}$ and $1.56,1.58,1.41$, and $1.07 \mathrm{~K} \mathrm{day}^{-1}$ over Kanpur, Barelliy, Pantnagar, and Nainital, respectively 
[38]. The estimated forcing and heating rate during the present analysis is comparable with these reported values. High surface cooling associated with significant atmospheric heating rate during the study period over both the locations may be capable of affecting the atmospheric dynamics.

\section{Summary and Conclusions}

The optical and radiative properties of aerosols have been studied over two sites situated in north-west region of India using the synergy of ground based and satellite observations. The major conclusions drawn from present study are as follows.

(I) The seasonal average mass concentration of coarser particulates $\left(\mathrm{PM}_{10}\right)$ is found to be high while concentrations of fine particulates $\left(\mathrm{PM}_{2.5}\right.$ and $\left.\mathrm{PM}_{1}\right)$ are low over Patiala than Dehradun.

(II) The pattern of AOD spectrum is mainly controlled by size of aerosols. The increase in AOD is more pronounced at higher wavelengths over Patiala relative to Dehradun and vice versa. It suggests an increase in coarse mode particles over Patiala and finer mode particles over Dehradun and these observations are further supported by Ångström coefficient and FMF analysis.

(III) Diurnal variation of BC is mainly controlled by atmospheric boundary layer dynamics and local anthropogenic activities. The BC concentration shows minima in the afternoon hours over both locations as compared to morning and evening hours. Seasonal value of $\mathrm{BC}$ mass concentration is higher over Patiala in comparison to Dehradun.

(IV) The SSA is wavelength dependent and its magnitude decreases with wavelength over Dehradun and increases with wavelength over Patiala. The low magnitude of SSA over Patiala is attributed to the abundance of more absorbing type of aerosols compared to Dehradun.

(V) The satellite derived AOD is in good agreement with ground measured AOD.

(VI) ARF ATM is estimated to be $+54.81 \mathrm{Wm}^{-2}$ over Patiala and $+37.34 \mathrm{Wm}^{-2}$ over Dehradun that leads to the heating rate of $1.0 \mathrm{~K} \mathrm{day}^{-1}$ and $1.5 \mathrm{~K} \mathrm{day}^{-1}$ over Dehradun and Patiala, respectively.

\section{Conflict of Interests}

The authors declare that there is no conflict of interests regarding the publication of this paper.

\section{Acknowledgments}

The present research work was carried out under ISRO-GBP research project and authors are grateful to ISRO for financial support. The authors would like to thank MODIS science data teams and NOAA Air Resources Laboratory (ARL) for the availability of HYSPILT model online. The meteorological data provided by IMD is duly acknowledged.

\section{References}

[1] R. J. Charlson, S. E. Schwartz, J. M. Hales et al., "Climate forcing by anthropogenic aerosols," Science, vol. 255, no. 5043, pp. 423430, 1992.

[2] J. M. Haywood and K. P. Shine, "The effect of anthropogenic sulfate and soot aerosol on the clear sky planetary radiation budget," Geophysical Research Letters, vol. 22, no. 5, pp. 603-606, 1995.

[3] J. Haywood and O. Boucher, "Estimates of the direct and indirect radiative forcing due to tropospheric aerosols: a review," Reviews of Geophysics, vol. 38, no. 4, pp. 513-543, 2000.

[4] J. E. Penner, X. Dong, and Y. Chen, "Observational evidence of a change in radiative forcing due to the indirect aerosol effect," Nature, vol. 427, no. 6971, pp. 231-234, 2004.

[5] J. Hansen, M. Sato, and R. Ruedy, "Radiative forcing and climate response," Journal of Geophysical Research D: Atmospheres, vol. 102, no. 6, pp. 6831-6864, 1997.

[6] V. Ramanathan, "Aerosol, climate and the hydrological cycle," Science, vol. 294, pp. 2119-2124, 2001.

[7] M. Kopacz, D. L. Mauzerall, J. Wang, E. M. Leibensperger, D. K. Henze, and K. Singh, "Origin and radiative forcing of black carbon transported to the Himalayas and Tibetan Plateau," Atmospheric Chemistry and Physics, vol. 11, no. 6, pp. 2837-2852, 2011.

[8] R. Kumar, M. Naja, S. K. Satheesh et al., "First ground based observations of influences of springtime Northern Indian biomass burning over the central himalayas," Journal of Geophysical Research, vol. 116, Article ID 19302, 2011.

[9] K. Ram, M. M. Sarin, and P. Hegde, "Atmospheric abundances of primary and secondary carbonaceous species at two highaltitude sites in India: sources and temporal variability," Atmospheric Environment, vol. 42, no. 28, pp. 6785-6796, 2008.

[10] U. C. Dumka, K. K. Moorthy, R. Kumar et al., "Characteristics of aerosol black carbon mass concentration over a high altitude location in the Central Himalayas from multi-year measurements," Atmospheric Research, vol. 96, no. 4, pp. 510-521, 2010.

[11] K. Ram, M. M. Sarin, and P. Hegde, "Long-term record of aerosol optical properties and chemical composition from a high-altitude site (Manora Peak) in Central Himalaya," Atmospheric Chemistry and Physics, vol. 10, no. 23, pp. 11791-11803, 2010.

[12] K. Ram, M. M. Sarin, and S. N. Tripathi, "A 1 year record of carbonaceous aerosols from an urban site in the Indo-Gangetic Plain: characterization, sources, and temporal variability," Journal of Geophysical Research D: Atmospheres, vol. 115, no. 24, Article ID D24313, 2010.

[13] D. R. Sikka, "Desert climate and its dynamics," Current Science, vol. 72, no. 1, pp. 35-46, 1997.

[14] N. Rastogi, A. Singh, D. Singh, and M. M. Sarin, "Chemical characteristics of $\mathrm{PM}_{2.5}$ at a source region of biomass burning emissions: evidence for secondary aerosol formation," Environmental Pollution, vol. 184, pp. 563-569, 2014.

[15] A. Singh, P. Rajput, D. Sharma, M. M. Sarin, and D. Singh, "Black carbon and elemental carbon from post-harvest agricultural-waste burning emissions in the Indo- Gangetic Plain," Advances in Meteorology, vol. 2014, Article ID 179301, 10 pages, 2014. 
[16] M. Morys, F. M. Mims III, S. Hagerup et al., "Design, calibration, and performance of MICROTOPS II handheld ozone monitor and Sun photometer," Journal of Geophysical Research D, vol. 106, no. 13, pp. 14573-14582, 2001.

[17] S. Kedia and S. Ramachandran, "Seasonal variations in aerosol characteristics over an urban location and a remote site in western India," Atmospheric Environment, vol. 45, no. 12, pp. 2120-2128, 2011.

[18] D. Sharma, D. Singh, and D. G. Kaskaoutis, "Impact of two intense dust storms on aerosol characteristics and radiative forcing over Patiala, Northwestern India," Advances in Meteorology, vol. 2012, Article ID 956814, 13 pages, 2012.

[19] A. D. A. Hansen, “The Aethalometer, manual, Magee Scientific, Berkeley, California, US," 2005.

[20] A. D. A. Hansen, V. N. Kapustin, V. M. Kopeikin, D. A. Gillette, and B. A. Bodhaine, "Optical absorption by aerosol black carbon and dust in a desert region of Central Asia," Atmospheric Environment A, vol. 27, no. 16, pp. 2527-2531, 1993.

[21] E. Weingartner, H. Saathoff, M. Schnaiter, N. Streit, B. Bitnar, and U. Baltensperger, "Absorption of light by soot particles: determination of the absorption coefficient by means of aethalometers," Journal of Aerosol Science, vol. 34, no. 10, pp. 1445-1463, 2003.

[22] T. C. Bond and R. W. Bergstrom, "Light absorption by carbonaceous particles: an investigative review," Aerosol Science and Technology, vol. 40, no. 1, pp. 27-67, 2006.

[23] A. D. A. Hansen, H. Rosen, and T. Novakov, "The aethalometer-an instrument for the real-time measurement of optical absorption by aerosol particles," Science of the Total Environment, vol. 36, pp. 191-196, 1984.

[24] A. D. A. Hansen, Magee Scientific Aethalometer User's Guide, Magee Scientific, Berkeley, Calif, USA, 1996.

[25] M. Hess, P. Koepke, and I. Schult, "Optical properties of aerosols and clouds: the software package OPAC," Bulletin of the American Meteorological Society, vol. 79, no. 5, pp. 831-844, 1998.

[26] S. S. Babu, S. K. Satheesh, and K. K. Moorthy, "Aerosol radiative forcing due to enhanced black carbon at an urban site in India," Geophysical Research Letters, vol. 29, no. 18, pp. 27.1-27.4, 2002.

[27] S. Ramachandran, R. Srivastava, S. Kedia, and T. A. Rajesh, "Contribution of natural and anthropogenic aerosols to optical properties and radiative effects over an urban location," Environmental Research Letters, vol. 7, no. 3, pp. 1-11, 2012.

[28] P. Ricchiazzi, S. Yang, C. Gautier, and D. Sowle, "BDART: a research and teaching software tool for plane-parallel radiative transfer in the Earth's atmosphere," Bulletin of the American Meteorological Society, vol. 79, no. 10, pp. 2101-2114, 1998.

[29] A. K. Prasad and R. P. Singh, "Changes in aerosol parameters during major dust storm events (2001-2005) over the IndoGangetic Plains using AERONET and MODIS data," Journal of Geophysical Research D: Atmospheres, vol. 112, no. 9, Article ID D09208, 2007.

[30] R. C. Levy, L. A. Remer, and R. G. Kleidman, "Global evaluation of the Collection 5 MODIS dark-target aerosol products over land," Atmospheric Chemistry and Physics, vol. 10, no. 6, pp. 14815-14873, 2010.

[31] Y. Shi, J. Zhang, J. S. Reid, B. Holben, E. J. Hyer, and C. Curtis, "An analysis of the collection 5 MODIS over-ocean aerosol optical depth product for its implication in aerosol assimilation," Atmospheric Chemistry and Physics, vol. 11, no. 2, pp. 557-565, 2011.
[32] S. Dey, S. N. Tripathi, R. P. Singh, and B. Holben, "Influence of dust storms on the aerosol optical properties over the Indo-Gangetic basin," Journal of Geophysical Research D: Atmospheres, vol. 109, no. 20, 2004.

[33] K. V. S. Badarinath, T. R. K. Chand, and V. K. Prasad, "Agriculture crop residue burning in the Indo-Gangetic plains," Current Science, vol. 91, no. 8, pp. 1085-1089, 2006.

[34] T. F. Eck, B. N. Holben, J. S. Reid et al., "Wavelength dependence of the optical depth of biomass burning, urban, and desert dust aerosols," Journal of Geophysical Research, vol. 104, no. 24, pp. 31333-31349, 1999.

[35] D. Ganguly, A. Jayaraman, and H. Gadhavi, "Physical and optical properties of aerosols over an urban location in western India: seasonal variabilities," Journal of Geophysical Research, vol. 111, Article ID D24206, 21 pages, 2006.

[36] K. Aruna, T. V. L. Kumar, D. Narayana, B. V. K. Murthy, S. S. Babu, and K. K. Moorthy, "Black carbon aerosols in a tropical semi-urban coastal environment: efects of boundary layer dynamics and long range transport," Journal of Atmospheric and Solar-Terrestial Physics, vol. 104, pp. 106-125, 2013.

[37] S. K. Satheesh, V. Vinoj, and K. K. Moorthy, "Radiative effects of aerosols at an urban location in southern India: observations versus model," Atmospheric Environment, vol. 44, no. 39, pp. 5295-5304, 2010.

[38] U. C. Dumka, S. N. Tripathi, A. Mishra et al., "Latitude variation of aerosol properties from Indo-Gangetic Plain to central Himalayan foothills during TIGERZ campaign," Journal of Geophysical Research: Atmosphere, vol. 119, pp. 1-20, 2014.

[39] A. K. Srivastava, S. Tiwari, P. C. S. Devara et al., "Premonsoon aerosol characteristics over the Indo-Gangetic Basin: implications to climatic impact," Annales Geophysicae, vol. 29, no. 5, pp. 789-804, 2011. 

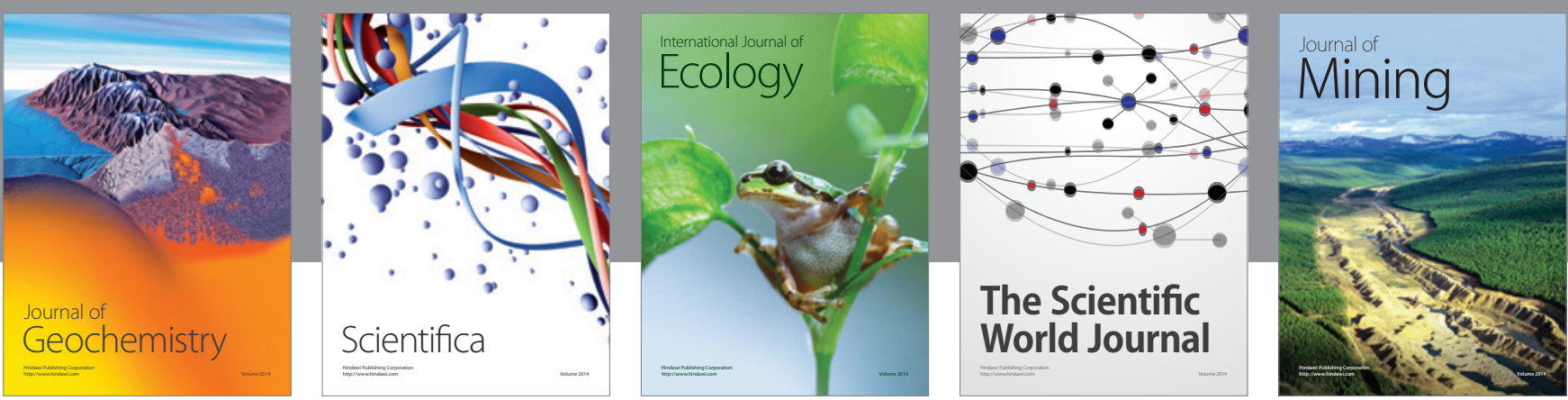

The Scientific World Journal
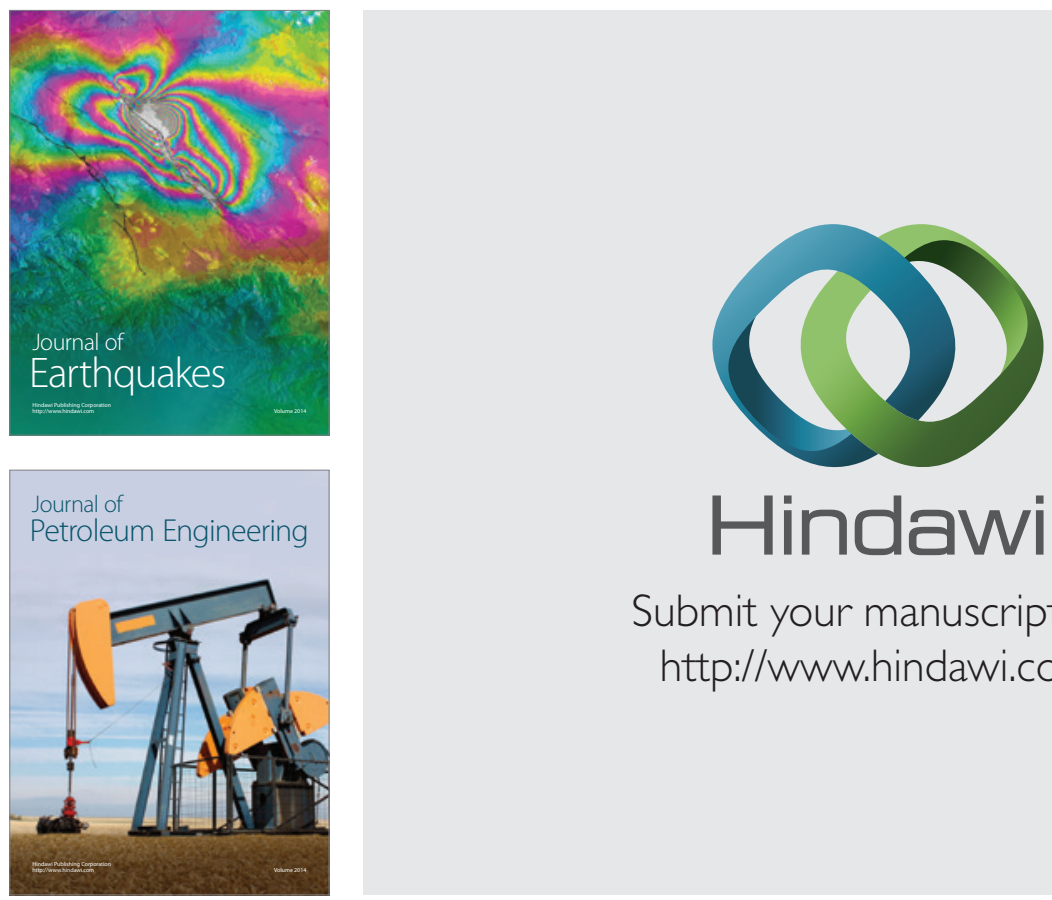

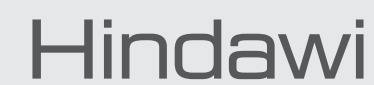

Submit your manuscripts at

http://www.hindawi.com
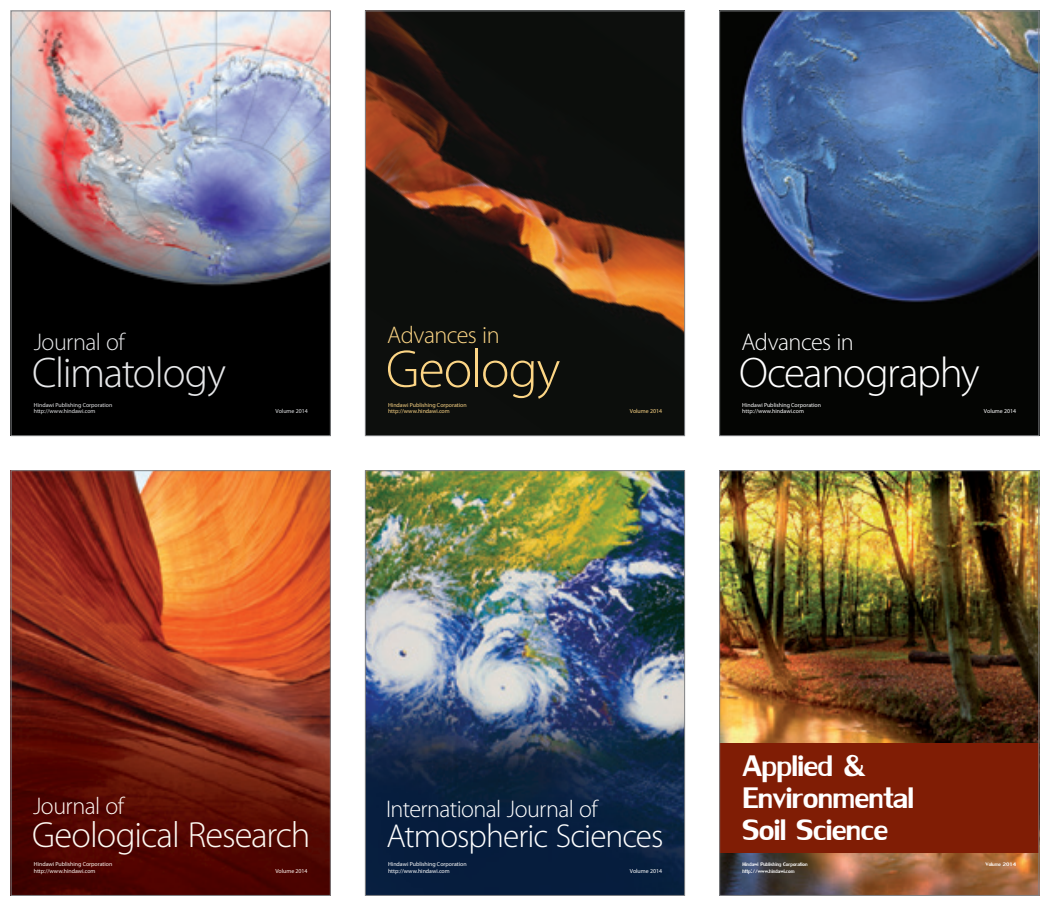
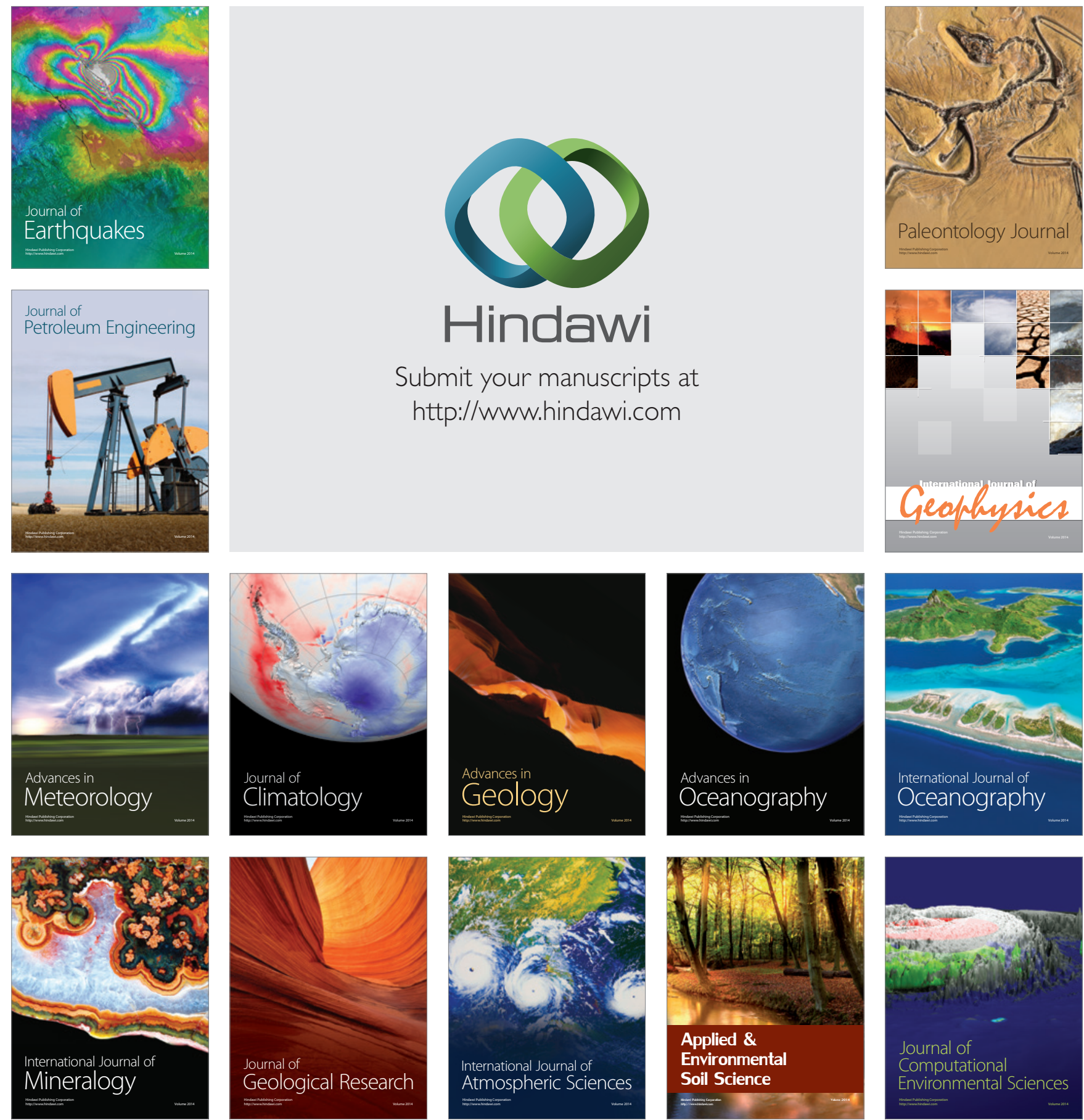